\title{
Fecundidad de Hemigrammus hyanuary
}

\author{
Fecundity of Hemigrammus hyanuary
}

Fecundidade de hyanuary de Hemigrammus

Elizabeth Aya - Baquero $^{1 *}$; José A. Arias Castellanos ${ }^{2 *}$

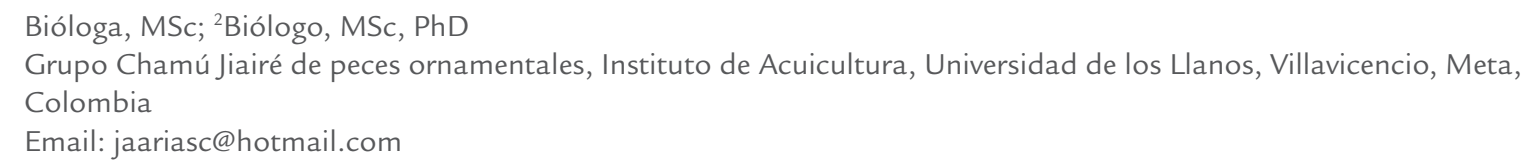

Recibido: septiembre 4 de 2012 Aceptado: noviembre 29 de 2012

\section{Resumen}

El conocimiento sobre la cantidad de huevos que una hembra es capaz de desovar en cada oportunidad reproductiva (fecundidad absoluta), es de gran importancia, pues de él depende el cálculo de las potencialidades reproductivas de la especie.

Hemigrammus hyanuary es un atractivo tetra de color amarillo oro al que debe su nombre de "tetra brillante". Hace parte del $4 \%$ de las exportaciones del país y vive en cardúmenes multiespecíficos. Es omnívoro y se reproduce durante toda la época de lluvias de la región de la Orinoquía.

Utilizando el método Gilson para la digestión de las gónadas, fueron estudiados los ovarios de veintidós hembras maduras de origen silvestre, de 4,2 $\pm 0,8 \mathrm{~g}$ de peso corporal, 3,2 $\pm 0,1 \mathrm{~cm}$ de longitud total y 0,041 $\pm 0,001 \mathrm{~g}$ de peso gonadal. Se determino la fecundidad absoluta, fecundidad relativa, el indicé gonadosomático y las frecuencias de los diámetros ovocitarios.

La fecundidad absoluta fue de $182 \pm 60$ ovocitos / hembra, mientras que la fecundidad relativa de $43 \pm 14$ ovocitos por g de peso corporal y el índice gonadosomático de 9,7 0,9. El histograma de frecuencia del diámetro de los ovocitos, así como el estudio histológico de las gónadas mostraron dos picos, lo que permite inferir que el desarrollo ovárico es asincrónico y explica los desoves parciales de la especie.

Palabras clave: desarrollo gonadal, diámetro ovocitario, fecundidad relativa, índice gonadosomático, tetra brillante

Key words: gonadal development, gonadosomatic index, oocyte diameter, relative fecundity, tetra bright 